\title{
Dimensional Measurement for Dentistry
}

\author{
Reisha Rafeek ${ }^{1}$, Kevin Seymour ${ }^{2}$ and Lifong Zou ${ }^{2}$ \\ ${ }^{1}$ School of Dentistry, University of the West Indies, \\ ${ }^{2}$ Barts and The London School of Medicine and Dentistry, \\ Queen Mary University of London, \\ ${ }^{1}$ Trinidad and Tobago \\ ${ }^{2}$ England
}

\section{Introduction}

Metrology is the science of measurement. Although it has been extensively used in the engineering and manufacturing fields for decades, measurement applications in dentistry are a relatively recent development. One of the major differences of measuring objects in dentistry is that the shape of human body parts are "free-form" rather than designed geometrical shapes used in industry.

\section{Main issue}

Dentistry requires development in hand skills throughout the undergraduate and postgraduate programs both in the pre-clinical and clinical settings (Allred, 1977). The level of expertise achieved depends on the level of training, the natural ability of the dentist and also experience. Tooth preparation for a crown is a common procedure in general dental practice and it is essential that dental students are able to perform this procedure competently before they graduate. The skill training of these techniques is in itself subjective, as there is use of "eyeballing" of the preparation rather than a definite measure. There is clearly a need to obtain more formal dimensional assessment of crown preparations. This will assist in the feedback to and the training of dentists and also in the practise of dentistry.

This chapter will describe dimensional measurements in dentistry with traditional solutions and present the use of metrology in dentistry. Metrology can benefit the teaching of dentistry by presenting three-dimensional images of teeth before and after preparation and measuring dimensional changes. This is also a benefit to the student as they are able to receive more objective measurable feedback. Metrology has also been used in dentistry to measure the amount of tooth wear on the surface of a tooth. Specifically in the preparation of crowns, it has been used previously to measure the width of the crown preparation margin, the angulation of the margin (Seymour et al.,1996, Cherukara et al., 2002) and the taper angle formed when a tooth is prepared for a crown (Rafeek et al., 2006, 2010).

\subsection{Traditional solutions}

The retention of a crown on a prepared tooth not only depends on the length and diameter of the walls of the preparation but also what is called the taper of the preparation. The angle 
formed between opposing walls of the tooth preparation for a crown is called taper or convergence angle (Rosenstiel, 1975). The retention of crowns decreases with increasing taper and has been shown to be inversely proportional to taper or convergence angle (Jorgenson, 1955). Therefore the higher the taper, the less retentive the crown and the more likely it will dislodge and come off the patient's tooth which is an undesirable outcome. The taper produced is in the hands of the dentist while the length and diameter of the walls are a function of the existing tooth. The ideal taper recommended is $4^{\circ}-14^{\circ}$ total convergence angle (Shillingburg et al., 1997) and some dental schools also recommend similar angles (Noonan \& Goldfogel, 1991; Robinson \& Lee, 2001). Taper has been measured previously by various methodologies using replicas of the tooth preparations called dies and a microscope (Ohm \& Silness, 1978), photocopying (Noonan \& Goldfogel, 1991), use of shadowgraphs (Weed et al., 1984; Sato et al., 1998), overhead projectors (Nordlander et al., 1988; Patel et al., 2005) and a goniometer microscope (Ayad et al., 2005).

The replicas of the teeth or dies are made from dental stone and these dies represent the tooth that has been prepared in the patient's mouth. The three dimensional shape has four sides and one top or occlusal surface. Two walls that oppose each other are called mesial and distal and the other two are called buccal and lingual. It is the angle formed by two opposing walls, for example between the buccal and lingual walls (in the bucco-lingual plane) which is measured as Figure 1.
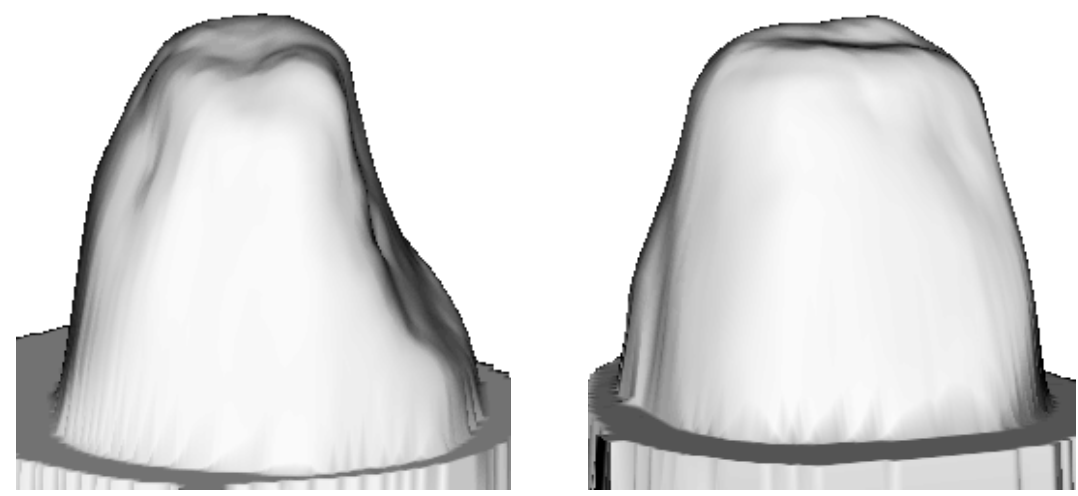

Fig. 1. Showing buccal and lingual walls (left) and mesial and distal walls (right)

Ohm and Silness (1978) projected the external contour lines of the preparation (of nearly 200 dies) and enlarged them onto the screen of the microscope and then measured the convergence angle. Noonan and Goldfogel (1991) used photocopy machines to copy over 900 dies. The dies were placed so that the shadow picture passed through the mesio-distal plane and then the images were produced on the copy paper. Lines were drawn on the surface planes of the shadow picture and the angle of convergence calculated.

Sato et al., (1998) investigated over 60 dies by projecting the silhouettes of the dies in a mesio-distal and bucco-lingual plane with a profile projector at magnification and traced them onto paper. Lines were drawn parallel to the walls and extended until they met and formed the convergence angle which was measured with a protractor. Patel et al., (2005) conducted investigations of convergence angle by also projecting silhouettes of 240 
sectioned dies onto a flat surface by means of an overhead projector. This methodology was used previously by Nordlander et al., (1988). The devices such as photocopiers and overhead projectors were inexpensive to use and easily available. However the projecting of the dies to produce silhouettes would produce some error due to a 3-D object being measured as a 2-D image. Also, with the overhead projector there may have been inaccuracy due to the magnification of the image.

Ayad et al., (2005) used a goniometer microscope to measure the convergence angle of silhouettes of almost 500 die specimens in the mesio-distal and bucco-lingual plane. The angle formed with one prepared wall e.g. the buccal wall, and the vertical crosshair within the focusing screen was measured in degrees with the vernier scale on the microscope. The taper or convergence angle was calculated by adding the buccal and opposing lingual measurements. The goniometer microscope is a more expensive device than the ones used previously but more highly accurate.

Several studies conducted using these traditional methodologies investigating tapers achieved by dental students have found mean tapers ranging from $11^{\circ}-27^{\circ}$ (Noonan \& Goldfogel, 1991; Robinson \& Lee, 2001; Smith et al., 1999; Mack, 1980; Ohm \& Silness, 1978; Sato et al., 1998; Patel et al., 2005; Ayad et al., 2005) while studies on specialists and general dental practitioners and have found mean tapers in the range $14^{\circ}-20^{\circ}$ (Patel et al., 2005; Nordlander et al., 1988; Kent et al., 1988; Eames et al., 1978). Even though higher than ideal tapers are found in some studies, tapers of up to $20^{\circ}$ have been shown to be clinically acceptable with only a few crowns that were reported to have loosened and lost retention or dislodged(Ohm \& Silness,1978; Sato et al., 1998).

\subsection{Proposed alternative}

This alternative to the traditional types of devices for measurement is a modern technology used in manufacturing industry called 3-D co-ordinate metrology. It has been very difficult to accurately measure the taper produced and these previous methodologies may have had errors. The use of the Co-ordinate Measuring Machine (CMM) is an attempt to more formally, consistently and accurately measure dimensional changes due to tooth preparation either at the margin of the crown, the angulation of that margin or the taper of the walls of the preparation. It characterises and defines the geometry of objects.

Free form surface measurement involves two key procedures, data acquisition and development of the correct fitting algorithm (Summerhays et al., 2002). Each of these problems has numerous solutions which largely depend upon the specified application. For example, the application of non-contact measurement methods has expanded into many new areas from traditional industrial applications; to the medical field, such as measurements of the human face and other parts of the human body (Aung et al., 1995; Shahrom et al., 1996; Fan, 1997). Gradually, researchers have required the process to be used on more complicated surfaces such as in the quantification of tooth morphology.

There are number of techniques currently used to obtain accurate surface measurements, each has its own strengths, weaknesses and areas of applicability. With surface form (shape) measurements, Co-ordinate Measuring Machines (CMMs) are more suited for the inspection of automotive parts in industry since the 1950's (Bosch, 1995). Since the late 90's, along with the development of new technology in optics and computing, numerous applications have 
been advanced in the fields of medicine and dentistry (Chadwick, 1989; Seymour et al. 1996; Kabban, et al. 2001; Zou, et al. 2001, 2009; Cherukara GP et al. 2002; Theocharopoulos et al., 2010; Morris et al. 2011 ).

The interface between the CMM and the measurement object or surface is a probe. The probe plays a very important role in obtaining the co-ordinates of a surface, and there are several kinds of probes commercially available at the present time. Touch trigger probes are by far the most commonly used with CMMs due to their simplicity and low cost. One of the problems with touch probes is that even under well-controlled conditions and at a generally accepted measuring speed and force, damage to the surface being scanned can occur because of the inertia effects of some probe parts (Win et al., 1998). Win also indicated that initial plastic yielding of a surface can easily occur when probing with a sphere, and at higher probing speeds, multiple bouncing of the probe may occur, which reduces the accuracy for all mechanical probe systems. The optical probe has the great advantage of non-contact with the surface being measured. By the late 1980's, non-contact laser probes were widely accepted for surface measurement, especially in free form surface digitisation techniques due to its fast speed in the digitisation. However the accuracy in measurement when using optical probes is affected by the reflectivity of the surface, for example, a rough or dark coloured surface which is often encountered, results in empty or distorted data readings at areas due to the surface low reflectivity.

\subsubsection{Surface digitisation technology}

Surface digitisation is a procedure by which digital data is acquired from a surface of interest in order to obtain more knowledge of the shape and dimensions of the object. This is achieved through a series of interactions between the measurement equipment and the surface being assessed. Digitisation usually provides a string of 3-D co-ordinates in ASCII format.

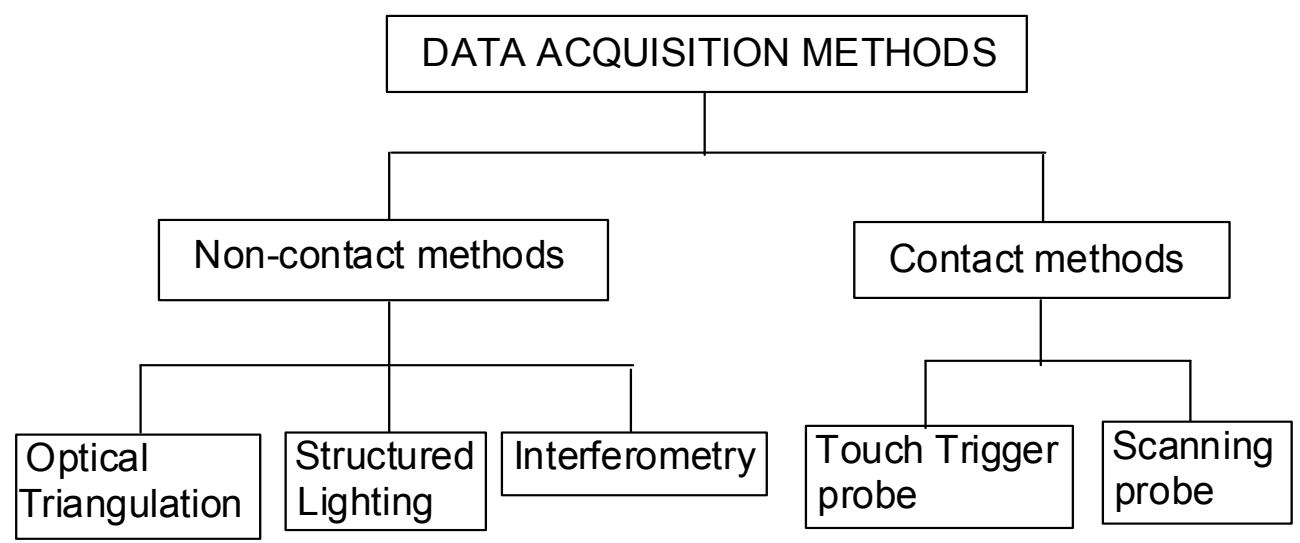

Fig. 2. A classification of data acquisition methods.

There are many different methods for acquiring co-ordinate data, as shown in Figure 2. Essentially, each method uses some mechanism or phenomenon for interacting with the surface of the object of interest. 
Contact methods use mechanical contact through a trigger or scanning probe at the end of an arm or the column of a CMM (Jarvis, 1983) to obtain surface geometrical information. Development of this method was driven by reverse engineering (Milroy et al., 1996; Dalton, 1998; Chow, 1997). In each case, an appropriate sensor determines a precise position on the object's surface.

Non-contact methods use scanning-type CMMs to capture larger numbers of sampling points, and have been used successfully for measuring surface form (Bradley and Vickers, 1992; Lee et al., 2001; Chang and Lin, 1999). A recent study comprising questionnaire respondents from research institutions and companies engaged in surface topography in the European Community, revealed that non-contact optical techniques are more popular and widely used than previously thought (Dong et al., 1994). Three dimensional non-contact measurement methods started to be used in the 1980's (Bosch, 1995; Stout, 1994).

The result of data acquisition is a discrete 'point cloud', through a 3-D analysis software it is interpolated into a 3-D surface and can be visualised as a 3-D object, furthermore to be analysed in its shape and dimensions.

With regard to the previously mentioned taper or convergence angle of prepared teeth; an angle measurement is taken at the middle of the mesial-distal plane where the central fissure runs through. The taper is the angle between the two lines along the two walls in this plane that passed the most outer points $\mathrm{A}$ and $\mathrm{B}$ which are located at the mesial and distal aspects as shown in Figure 3.

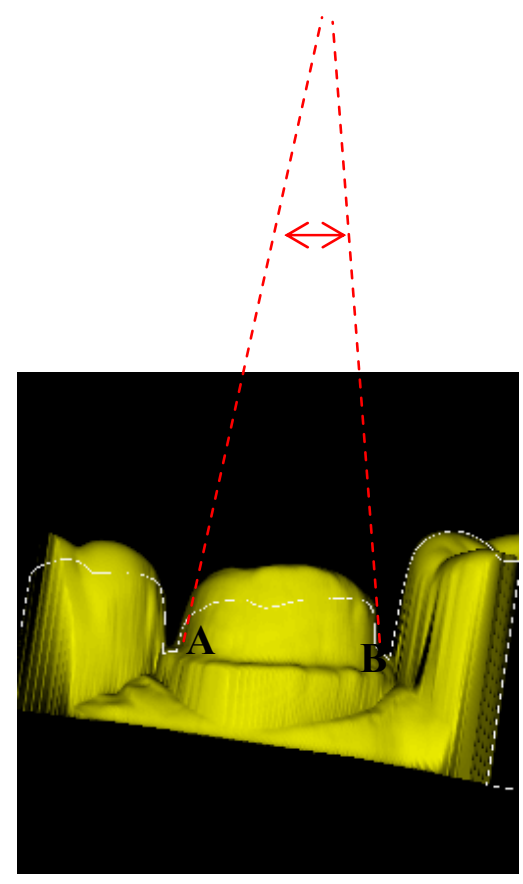

Fig. 3. The angle measurement between mesial and distal walls 


\subsection{Experimental measurements}

Experimental studies were conducted in order to assess the taper of teeth prepared for crowns by dental students. Teeth were prepared both in the clinical setting on live patients and also on artificial plastic teeth set in a manikin phantom head jaw in a preclinical laboratory. It would then not only be possible to measure taper achieved but to also compare this with other dental schools.

Dental students are first taught to carry out crown preparations in a laboratory based course with didactic sessions of lectures and handouts. There are also practical sessions with live demonstrations projecting magnified images on television monitors via video cameras of the procedure in detail. They are taught to create a preparation with a $6^{\circ}$ taper by holding a $3^{\circ}$ tapered bur parallel to the long axis of the tooth while cutting each wall (Shillingburg et al., 1997). The students are then expected to perform the procedures until satisfactory and then pass practical examinations for that procedure prior to being allowed to perform the procedure on a patient.

The specimens used were obtained from both crown preparations carried out by students for their practical examinations in the laboratory and also from crown preparations done in the clinic on patients. There were 99 laboratory specimens or dies and 40 clinical dies. In order to form the replicas or dies of the tooth preparations an impression of the tooth has to be taken. This was done by using addition cured polyvinylsiloxane impression material, Reprosil (Dentsply Caulk, Milford DE, USA). The technician who fabricated the crowns used the first pour of the impression to fabricate the actual crown that was fitted onto the tooth. The impression can be used again for a second pour in order to make the die that was used to measure the taper. This second use of this type of impression has been shown to be as accurate as the first pour (Johnson \& Craig, 1985). The die stone used to pour into the impression to create the die replica was Type IV (Vel Mix) (Kerr Corp., Orange CA, USA) and was mixed under vacuum and poured. The material was left to set and the standing base of the dies were trimmed specifically to be flat to the long axis of the prepared tooth and the sides of the base were also milled so that the buccal and lingual were parallel to each other and the mesial and distal parallel to each other.

The die spacer (Quick Set Die Spacer Blue, Belle de St. Claire, (Kerr Corp., Orange CA, USA) was painted over the crown preparations in 2 layers according to manufacturer's instructions, as is the usual procedure when fabricating crowns. This also overcame the incompatibility of the pink stone to the probe and was needed in order for the scanning machine to effectively read the preparation, allowing the probing tracer to follow the surface profile rather than the details of the surface texture.

The die stone replica was fixed in a clamping device and digitised by the purpose built dental scanner Incise (Renishaw, UK) with a scanning probe of SM25-1 (Renishaw, UK) shown in Figure 4 . The digitisation is conducted by Tracecut Controlling Software Package (Renishaw, UK). The probe tip is made of industrial ruby of a sphere with $1 \mathrm{~mm}$ diameter and it has been calibrated before the digitisation process. The digitisation procedure was defined as such: the sampling interval in both $X$ and $Y$ directions was $0.1 \mathrm{~mm}$, and scanning speed was 200 points per minutes, and scanning deflection is $0.5 \mathrm{mg}$. The data cloud was interpolated as a surface by using a 3-D free form surface analysis software - Cloud (UCL, $\mathrm{UK})$. The degree of taper of the prepared tooth was determined in a bucco-lingual (BL) plane and mesio-distal (MD) plane. 


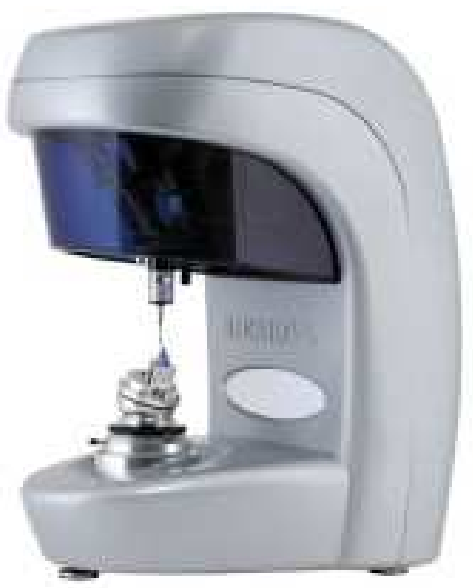

Fig. 4. Incise dental scanner (Renishaw, UK)

All results were recorded and data were analysed by means of a one-way analysis of variance (ANOVA) and student $t$ tests for any significant differences.

\subsection{Results}

The results of this experiment were published by Rafeek et al., (2010). There were no undercuts detected on any of the laboratory specimens as compared to the clinical specimens where $12.5 \%$ were undercut. The overall mean taper for the laboratory specimens was $22.5^{\circ}(\mathrm{BL})$ and $14.5^{\circ}(\mathrm{MD})$. The overall mean taper for the clinical specimens was $24.2^{\circ}$ (BL) and $19.6^{\circ}(\mathrm{MD})$. Table 1 shows the percent of specimens falling within the ideal taper range of $4^{\circ}-14^{\circ}$.

\begin{tabular}{|c|c|c|}
\hline Specimens & BL taper between $4^{\circ}-14^{\circ}$. & MD taper between $4^{\circ}-14^{\circ}$. \\
\hline Laboratory & $28 \%$ & $54 \%$ \\
\hline Clinical & $28 \%$ & $25 \%$ \\
\hline
\end{tabular}

Table 1 . Shows the percentage of tapers falling within the ideal range of $4^{\circ}-14^{\circ}$.

Although the mean tapers achieved in the laboratory compared to the clinic were lower, there was no significant difference detected between the mean tapers achieved $(p>0.05)$ except for the MD taper of posterior teeth $(\mathrm{p}<0.05)$.

\subsection{Discussion}

The overall mean tapers achieved were higher than the recommended range of $4^{\circ}-14^{\circ}$ however the results were similar to many other clinical studies involving dental students. Table 2 summarises the comparisons of mean taper achieved in this study versus those measured with traditional devices. 


\begin{tabular}{|c|c|c|}
\hline $\begin{array}{c}\text { CLINICAL SPECIMENS } \\
\text { (Posteriors) }\end{array}$ & BL mean taper & MD mean taper \\
\hline $\begin{array}{c}\text { Rafeek et al., 2010 } \\
\text { (Trinidad dental school) }\end{array}$ & $16.8^{\circ}$ & $18.5^{\circ}$ \\
\hline $\begin{array}{c}\text { Noonan \& Goldfogel, 1991 } \\
\text { (US dental school) }\end{array}$ & $19.5^{\circ}$ & $19.2^{\circ}$ \\
\hline $\begin{array}{c}\text { Sato et al., 1998 } \\
\text { (Japanese dental school) }\end{array}$ & $18.8^{\circ}$ & $16.3^{\circ}$ \\
\hline $\begin{array}{c}\text { Patel et al.,2005 } \\
\text { (UK dental school) }\end{array}$ & $14.7^{\circ}$ & MD mean taper $^{\circ}$ \\
\hline $\begin{array}{c}\text { LABORATORY SPECIMENS } \\
\text { (Posteriors) }\end{array}$ & BL mean taper & $14.2^{\circ}$ \\
\hline $\begin{array}{c}\text { Rafeek et al., 2010 } \\
\text { (Trinidad dental school) }\end{array}$ & $18.2^{\circ}$ & $14-^{\circ} 20^{\circ}$ \\
\hline $\begin{array}{c}\text { Ayad et al., 2005 } \\
\text { Egyptian, US and Saudi } \\
\text { Arabian dental schools }\end{array}$ & $15^{\circ}-20^{\circ}$ & \\
\hline
\end{tabular}

Table 2. Comparison of mean bucco-lingual (BL) and mesio-distal (MD) tapers of Clinical and Laboratory specimens with this study and studies utilising traditional methodology.

The comparisons of these data demonstrate that dental students in the Trinidad dental school have produced tapers that are comparable to dental students in many other dental schools around the world (Noonan \& Goldfogel, 1991; Sato et al., 1998; Patel et al., 2005; Ayad et al., 2005; Mack, 1980). The dental students in the metrology study not only achieved mean tapers comparable to other students but also to dentists in a US study (Nordlander et al., 1988).

Because of the varying methods used to measure taper in the past, one must compare data with caution, however, it would appear from this work that measurements made by 3-D coordinate metrology are in close range of several studies previously undertaken. The traditional methodologies however do involve forming a two dimensional profile from the three dimensional die replica. This in itself can introduce error. This 3-D coordinate metrology is unique in that it is truly 3-D free-form surface digitisation, rather than 2-D profiling. The software is also able to use the image in a particular requested plane, therefore the taper angles can be calculated in the same plane for each of the samples. This reduces the possible error in angle calculation due to the samples being misaligned. It would be useful to measure the taper of the dies using traditional devices and then measure the taper of the same dies using CMM and compare the data to determine how closely they measure up.

\subsection{Standards around the area}

Although dimensional measurements have been widely applied in dental research, for some of the measurements, such as taper angle measurement, a consensus has been demonstrated (Noonan \& Goldfogel, 1991; Sato et al., 1998; Patel et al., 2005; Ayad et al., 2005; Mack, 1980; Rafeek et al., 2006, 2010). In other areas, such as tooth wear measurements (Zhou and 
Zheng, 2008; Pintado MR et al, 2000; Mitchell and Chadwick, 1998) this has not been the case. There have been some 640 papers published in tooth wear measurement over the period of 1960 to 2007, and the measurements within these papers are wide ranging using a clinical tooth wear index, a modified index, reduced depth of tooth surface in the laboratory, reduced volume and changes in percentage of the area or volume. Moreover the accuracy of these measurements were reported by accuracy, precision, inaccuracy, error and uncertainty, which demonstrated a lack of a standard in the measurement strategy, therefore it is often difficult to compare the results directly between the laboratories and published papers. The ISO is in the process of establishing and organising a committee for the dental computer assisted design-computer assisted manufacture (CAD/CAM) and its related issues so that more formal standards and protocols may be set up to improve dimensional measurements in dentistry. However, this standard will not assist in the comparison of research data, where the inaccuracies listed above are inherent. Employment of instruments with high levels of accuracy such as the CMM as a 'norm' in this type of clinical research would enable data from different laboratories to be compared at the appropriate level and power and thus enable more meaningful conclusions to be made.

\section{Conclusion}

The 3-D coordinate metrology described study shows that the taper achieved by dental students of the Trinidad dental school when preparing teeth for crowns was comparable to those achieved by other students in the US, UK, Europe, Japan, Egypt and Saudi Arabia. The study also demonstrates a method for measurement of free form oral surfaces that has enormous potential. As 'digital' dentistry develops, there is a need for worldwide standards and quality control and 3-D coordinate metrology is an extremely useful tool for this at both preclinical and clinical stages. In addition, the use of 3-D coordinate metrology in dental education, where the student is able to get 3-D visual 'feedback' of preparations in the laboratory is a valuable experience in the 'rehearsal' scenario. Lessons learned in this scenario can then be transferred to the clinic and the treatment of patients, where improved preparation quality will inevitably lead to fewer crowns requiring to be remade with all the attendant stress for both patient and clinician.

3-D coordinate metrology also has the ability to be used in a variety of areas of dental research, in particular in relation to tooth wear which is becoming an increasing global problem.

\section{References}

Allred H (1977). A series of monographs on the assessment of the quality of dental care. The London Hospital Medical College.

Ayad MF, Maghrabi AA, Rosenstiel SF (2005). Assessment of convergence angles of tooth preparations for complete crowns among dental students. Journal of Dentistry, 33: pp 633-638

Aung SC, Ngim RCK \& Lee ST (1995). Evaluation of the laser scanner as a surface measuring tool and its accuracy compared with direct facial anthropometric measurements. British Journal of Plastic Surgery, Vol.48, pp 551-558. 
Bosch J A(Ed.) (1995). Co-ordinate measuring machines and systems, Marcel Dekker, INC, ISBN 0-8247-9581-4, New York, USA.

Bradley C \& Vickers GW (1992). Automated rapid prototyping utilizing laser scanning and free-form machining, Ann CIRP, pp 437-440.

Chang M \& Lin PP (1999). On-line free form surface measurement vial a fuzzy-logic controlled scanning probe. International Journal of Machine tools and manufacture, Vol.39, pp 539-552.

Chadwick RG (1989). A review: the assessment of the durability of composite resin restorative materials in vivo. Clinical Materials. 4, pp 241-253.

Cherukara GP, Seymour KG, Samarawickrama DYD, Zou LF (2002). A study into the variations in the labial reduction of teeth prepared to receive porcelain veneers - $\mathrm{a}$ comparison of three clinical techniques. British Dental Journal 192: pp $401-404$.

Chow JG (1997). Reproducing aircraft structural components using laser scanning. International Journal of Advanced Manufacturing Technology, Vol.13, pp 723-728.

Dalton G (1998). Reverse engineering using laser metrology. Sensor review, Vol.18, No.2, pp 92-96.

Dong WP, Mainsah E, Stout KJ \& Sullivan PJ (1994). Three-dimensional surface topography:Review of present and future trends, Part II of Three-dimensional surface topography: measurement, interpretation and applications (Ed, Stout KJ), Penton Press, ISBN 1857180046.

Eames WB, O'Neal SJ, Monteiro J, Miller C, Roan JD \& Cohen KS. Techniques to improve the seating of castings (1978). Journal of the American Dental Association, 96: pp 432437.

Fan KC (1997). A non-contact automatic measurement for free-form surface profiles, Computer integrated manufacturing systems, Vol.10, No.4, pp 277-285.

Jarvis RA (1983). A perspective on range finding techniques for computer vision. IEEE Pattern Anal Mach Intell, Vol.5, No.2, pp 122-139.

Johnson GH, Craig RG (1985). Accuracy of four types of rubber impression materials compared with time of pour and a repeat pour of models. Journal of Prosthetic Dentistry, 53: pp 484-490.

Jorgensen KD (1955). The relationship between retention and convergence angle in cemented veneer crowns. Acta Odontologica Scandinavica, 13, pp 35-40.

Kabban M, Fearne J, Jovanovski V \& Zou L (2001). Tooth size and morphology in twins; International Journal of Paediatric Dentistry, Vol.11, pp 333-339.

Kent WA, Shillingburg HT, Duncason MG (1988). Taper of clinical preparations for cast restorations. Quintessence International, 19, pp 339-345.

Lee KH, Park H \& Son S (2001). A framework for laser scan planning of freeform surfaces; International Journal of Advance Manufacturing Technology, Vol.17, pp 171-80.

Mack PJ (1980). A theoretical and clinical investigation into the taper achieved on crown and inlay preparations. Journal of Oral Rehabilitation, 7, pp 255-265.

Milroy M J, Weir D J, Bradley C \& Vickers G W (1996). Reverse engineering employing a 3-D laser scanner: a case study. International Journal of Advanced Manufacturing technology, Vol.12, pp 111-121.

Mitchell H L and Chadwick R G (1998). Mathematical shape matching as a tool in tooth wear assessment - development and conduct. Journal of Oral Rehabilitation Vol.25, pp 921-8. 
Morris BO, Zou L, Royle M \& Shelton C (2011). Wear Assessment of Metal-on-Metal Acetabular Cups Using a Coordinate Measuring Machine. Wear 271, pp 1086-1092.

Noonan JE \& Goldfogel MH (1991). Convergence of axial walls of full veneer crown preparations in a dental school environment. Journal of Prosthetic Dentistry, 66, pp 706-708.

Nordlander J, Weir D, Stoffer W, et al. (1988). The taper of clinical preparations for fixed prosthodontics. Journal of Prosthetic Dentistry, 60, pp 148-151.

Ohm H \& Silness J (1978). The convergence angle in teeth prepared for artificial crowns. Journal of Oral Rehabilitation, 5, pp 371-375.

Patel PB, Wildgoose DG \& Winstanley RB (2005).Comparison of convergence angles achieved in posterior teeth prepared for full veneer crowns. European Journal of Prosthodontics and Restorative Dentistry, 13, pp 100-104.

Pintado MR, Delong R, Ko CC, Sakaguchi RL \& Douglas WH (2000); Correlation of noncarious cervical lesion size and occlusal wear in a single adult over a 14-year time span; The Journal of Prosthetic Dentistry, Vol.84, No.4 pp 436-43.

Rafeek RN, Marchan SM, Seymour, Zou LF \& Samarawickrama DYD (2006). Abutment taper of full cast crown preparations by dental students in the UWI School of Dentistry. European Journal of Prosthodontics and Restorative Dentistry, 2, pp 63-66.

Rafeek RN, Smith WA, Seymour KG, Zou LF \& Samarawickrama DYD (2010). Taper of fullveneer crown preparations by dental students at the University of the West Indies. Journal of Prosthodontics, Oct, 19(7), pp 580-585.

Robinson PB \& Lee JW (2001). The use of real time video magnification for the pre-clinical teaching of crown preparations. British Dental Journal, 190(9), pp 506-510.

Rosenstiel E (1975). The taper of inlay and crown preparations. British Dental Journal, 139, pp 436-438.

Sato T, Mutawa N, Okada D \& Hasegawa S (1998). A clinical study on abutment taper and height of full cast crown preparations. Journal of Medical and Dental Sciences, 45, pp 205-210.

Seymour KG, Zou LF, Samarawickrama DYD \& Lynch E (1996). Assessment of shoulder dimensions and angles of porcelain bonded to metal crown preparations. Journal of Prosthetic Dentistry, 75,pp $406-411$.

Shahrom AW, Vanezis P, Chapman RC, Gonzales A, Blenkinsop C \& Rossi M L (1996). Techniques in facial identification:computer aided facial reconstruction using a laser scanner and video superimposition. International Journal of Legal Medicine, Vol.108, pp 194-200.

Shillingburg H, Hobo S, Whitsett LD, et al. (1997). Fundamentals of fixed prosthodontics. Chicago; Quintessence., pp119-138.

Smith CT, Gary JJ, Conkin JE, et al. (1999). Effective taper criterion for the full veneer crown preparation in preclinical prosthodontics. Journal of Prosthodontics, 8, (3), pp 196200.

Stout K J (1994). Three-dimensional surface topography: measurement, interpretation and applications; Penton press; ISBN 1857180046.

Summerhays K D, Henke R P, Baldwin J M, Cassou RM \& Brown CW (2002). Optimizing discrete point sample patterns and measurement data analysis on internal cylindrical surfaces with systematic form deviations. Precision engineering, Journal of the International Societies for precision engineering and nanotechnology, vol.26 pp 105-121. 
Theocharopoulos A, Zou L, Hill R \& Cattell M (2010). Wear quantification of human enamel and dental glass-ceramics using white light profilometry. Wear 269, pp 930-936.

Weed RM, Suddick RP, Kleffner JH (1984). Taper of clinical and typodont crowns prepared by dental students. (Abstract) Journal of Dental Research, 63, pp 286.

Win P, Van Vliet W \& Schellekens P (1998). Development of a fast mechanical probe for coordinate measuring machines. Precision engineering, Journal of the International Societies for precision engineering and nanotechnology, 22, pp 141-152.

Zhou Z R \& Zheng J (2008); Tribology of dental materials: A Review. Journal of Physics D Applied physics, Vol.41, pp 113001-23.

Zou L, Cherukara G, Hao P, Seymour K \& Samarawickrama DYD (2009). Geometrics of tooth wear. Wear Vol.266, pp 205-208.

Zou L, Samarawickrama DYD, Jovanovski V \& Shelton J (2001). Measurements of sequential impressions of acetabula cups from a total hip joint replacement using a noncontact measurement system. International Journal of Machine tools $\mathcal{E}$ manufacture, Vol.41, pp 2023-2030. 


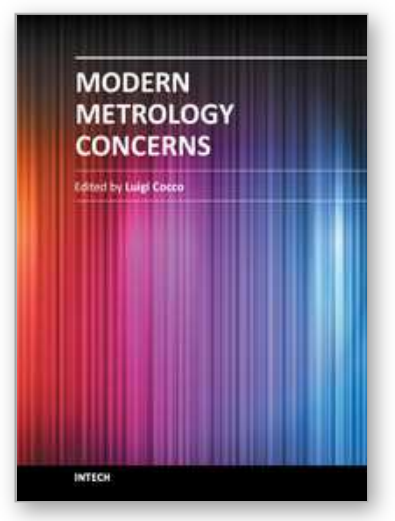

\author{
Modern Metrology Concerns \\ Edited by Dr. Luigi Cocco
}

ISBN 978-953-51-0584-8

Hard cover, 458 pages

Publisher InTech

Published online 16, May, 2012

Published in print edition May, 2012

"What are the recent developments in the field of Metrology?" International leading experts answer this question providing both state of the art presentation and a road map to the future of measurement science. The book is organized in six sections according to the areas of expertise, namely: Introduction; Length, Distance and Surface; Voltage, Current and Frequency; Optics; Time and Relativity; Biology and Medicine. Theoretical basis and applications are explained in accurate and comprehensive manner, providing a valuable reference to researchers and professionals.

\title{
How to reference
}

In order to correctly reference this scholarly work, feel free to copy and paste the following:

Reisha Rafeek, Kevin Seymour and Lifong Zou (2012). Dimensional Measurement for Dentistry, Modern Metrology Concerns, Dr. Luigi Cocco (Ed.), ISBN: 978-953-51-0584-8, InTech, Available from:

$\mathrm{http}: / /$ www.intechopen.com/books/modern-metrology-concerns/dimensional-measurement-for-dentistry

\section{INTECH}

open science | open minds

\author{
InTech Europe \\ University Campus STeP Ri \\ Slavka Krautzeka 83/A \\ 51000 Rijeka, Croatia \\ Phone: +385 (51) 770447 \\ Fax: +385 (51) 686166 \\ www.intechopen.com
}

\author{
InTech China \\ Unit 405, Office Block, Hotel Equatorial Shanghai \\ No.65, Yan An Road (West), Shanghai, 200040, China \\ 中国上海市延安西路65号上海国际贵都大饭店办公楼 405 单元 \\ Phone: +86-21-62489820 \\ Fax: $+86-21-62489821$
}


(C) 2012 The Author(s). Licensee IntechOpen. This is an open access article distributed under the terms of the Creative Commons Attribution 3.0 License, which permits unrestricted use, distribution, and reproduction in any medium, provided the original work is properly cited. 